\title{
A comparison of methods for purification and concentration of norovirus GII-4 capsid virus-like particles
}

\author{
L. Huhti $\cdot$ V. Blazevic $\cdot$ K. Nurminen • \\ T. Koho $\cdot$ V. P. Hytönen $\cdot$ T. Vesikari
}

Received: 4 June 2010/ Accepted: 22 July 2010/Published online: 19 August 2010

(C) The Author(s) 2010. This article is published with open access at Springerlink.com

\begin{abstract}
Noroviruses (NoVs) are one of the leading causes of acute gastroenteritis worldwide. NoV GII-4 VP1 protein was expressed in a recombinant baculovirus system using Sf9 insect cells. Several methods for purification and concentration of virus-like particles (VLPs) were evaluated. Electron microscopy (EM) and histo-blood group antigen (HBGA) binding assays showed that repeated sucrose gradient purification followed by ultrafiltration resulted in intact VLPs with excellent binding to $\mathrm{H}$ type 3 antigens. VLPs were stable for at least 12 months at $4{ }^{\circ} \mathrm{C}$, and up to 7 days at ambient temperature. These findings indicate that this method yielded stable and high-quality VLPs.
\end{abstract}

Noroviruses (NoVs) cause sporadic acute nonbacterial gastroenteritis in all age groups [12,13]. NoVs are divided into five genogroups, GI to GV, of which GI and GII strains mostly affect humans [21]. Recently, NoV genotype GII-4 has been responsible for the majority of sporadic gastroenteritis cases and outbreaks [13]. The NoV genome consists of a single-stranded RNA of about $7.6 \mathrm{~kb}$, organized into open reading frames (ORF 1-3). ORF-1 codes for the

L. Huhti $(\bowtie) \cdot$ V. Blazevic · K. Nurminen · T. Vesikari

Vaccine Research Center, University of Tampere Medical

School, Biokatu 10, 33520 Tampere, Finland

e-mail: 11lete@uta.fi

T. Koho $\cdot$ V. P. Hytönen

Institute of Medical Technology, Tampere University Hospital,

University of Tampere, Tampere, Finland

T. Vesikari

Department of Pediatrics, Tampere University Hospital,

Tampere, Finland
RNA-dependent RNA polymerase, and ORF-2 and -3 encode the two structural proteins VP1 and VP2 [10].

Expression of the capsid VP1 gene by recombinant baculoviruses leads to self-assembly into empty virus-like particles (VLPs) that are morphologically and antigenically similar to native NoV [9]. NoV VLPs are widely used as antigens in diagnostic serological assays and as candidate vaccines against NoVs $[2,7]$. NoV VLPs are highly stable and resistant to variable conditions, particularly to low $\mathrm{pH}$ $[1,9]$.

There are limitations in NoV VLP production in terms of inadequate yield and quality of the VLPs [1, 3, 9, 20]. Both sucrose and $\mathrm{CsCl}$ gradients ultracentrifugation have been used for purification of NoV VLPs [1, 7, 9, 17], even though studies on rotavirus-like particles demonstrated a low yield and impurities resulting from $\mathrm{CsCl}$ gradient purification [16].

In the present study, we compared commonly used methods for NoV GII-4 VLP purification [1, 14, 17] and concentration [6, 19], considering the purity, yield, morphological integrity, antigenicity and functionality of the purified VLPs.

The steps for cloning the NoV GII-4 (GenBank sequence database accession number AF080551) full-length capsid gene are described elsewhere [11].

VLPs were produced in $\mathrm{Sf} 9$ insect cells infected with the recombinant baculovirus according to the manufacturer's instructions (Invitrogen, Carlsbad, CA). Baculovirus titers expressed as the multiplicity of infection (MOI) of the P2 stocks were determined using a BacPak Rapid Titer Kit (Clontech Laboratories, Mountain View, CA).

At day 6 , infected cell culture $(200 \mathrm{ml})$ was clarified by centrifugation at $3000 \times g$ for $30 \mathrm{~min}$ at $4{ }^{\circ} \mathrm{C}$. VLPs in the supernatant were concentrated by ultracentrifugation (L8-60M ultracentrifuge, Beckman SW-32.1 Ti rotor) at 
$100,000 \times g$ for $2 \mathrm{~h}$ at $4^{\circ} \mathrm{C}$, and pellets were resuspended in $0.2 \mathrm{M}$ Tris- $\mathrm{HCl}, \mathrm{pH}$ 7.3. VLPs were loaded onto a $10-60 \%$ discontinuous sucrose gradient and ultracentrifugated at $100,000 \times g$ for $1 \mathrm{~h}$ at $4^{\circ} \mathrm{C}$ as described before [17]. Fractions were collected by bottom puncture. The fractions containing VLPs were pooled. An additional discontinuous sucrose gradient $(35-60 \%)$ ultracentrifugation was performed. Sucrose was removed by overnight dialysis against 1 liter of PBS. VLPs were concentrated by dialysis against polyethylene glycol (PEG; 50\%) [6] or by ultrafiltration [19]. VLPs were concentrated using an Amicon Ultra $30 \mathrm{kDa}$ centrifuge filter device (Millipore Corporation, Billerica, Germany). VLPs were stored at $4^{\circ} \mathrm{C}$ in PBS.

Alternatively, a less time-consuming sucrose density gradient purification method was employed [14]. Clarified supernatants were pelleted twice by ultracentrifugation.

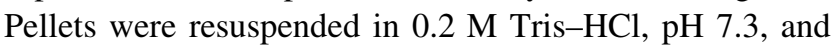
placed on a discontinuous sucrose density gradient (10-60\%) for ultracentrifugation at $100,000 \times g$ for $16 \mathrm{~h}$ at $4^{\circ} \mathrm{C}$. The VLP band, which was visible at the $35 \%$ sucrose layer, was collected. Sucrose was removed by dialysis against 1 liter of PBS, and VLPs were concentrated by ultracentrifugation at $100,000 \times g$ for $2 \mathrm{~h}$ at $4^{\circ} \mathrm{C}$.

In addition, clarified supernatants were concentrated, and the pellets were resuspended in sterile water. VLPs were sedimented by ultracentrifugation through cesium chloride $(\mathrm{CsCl})(0.4 \mathrm{~g} / \mathrm{ml})$ at $116,000 \times g$ for $18 \mathrm{~h}$ at $4^{\circ} \mathrm{C}$ as described earlier by others [1]. $\mathrm{CsCl}$ was removed by dialysis against PBS, and VLPs were concentrated using an Amicon Ultrafilter.

The total protein content of the purified VLP preparation was determined using the Pierce BCA Protein Assay (Thermo Science, Rockford, USA). Endotoxin levels in the VLP preparations were quantified using the Limulus amebocyte lysate (LAL) assay (Lonza, Walkersville, MD, USA). The level of endotoxin was $<0.1 \mathrm{EU} / 10 \mu \mathrm{g}$ of protein, which is below the international standard of $\leq 30 \mathrm{EU} / 20 \mu \mathrm{g}$ of protein [15]. All samples were analyzed for protein expression by sodium dodecyl sulphate-polyacrylamide gel electrophoresis (SDS-PAGE) and western blot. The presence of NoV VLPs was verified by electron microscopy (EM). VLP preparations were negatively stained with $3 \%$ uranyl acetate (UA), pH 4.6. The VLPs were examined using an FEI Tecnai F12 electron microscope operating at $120 \mathrm{kV}$.

Binding of GII-4 VLPs to carbohydrate receptors was examined by the histo-blood group antigen (HBGA) binding assay as described by others [18], with slight modifications. Briefly, VLPs were coated at $50 \mathrm{ng} /$ well, and synthetic biotinylated $\mathrm{H}$ type 3 and Lewis ${ }^{\mathrm{b}}$ histo-blood group carbohydrates (Lectinity Holdings Inc. Moscow, Russia) were used in serial threefold dilutions, starting from $6 \mu \mathrm{g} / \mathrm{ml}$. Wells lacking the synthetic carbohydrates were used as a negative control.
The conditions for Sf9 cell infections were optimized in order to obtain a high yield of the VLPs. For recombinant baculovirus P2 stock, an MOI of 1 was found to be optimal, and VLPs were harvested from the supernatant after 6 days of infection. VLPs were further purified by several different procedures, as described in Fig. 1a.

The best yield $(2-3 \mathrm{mg} / 200 \mathrm{ml})$ was obtained after the purification procedure described in Fig. 1a, panel B. In comparison, the method described in Fig. 1a, panel C, yielded a ten times lower amount of NoV capsid VLPs. The purity of the VLPs obtained by each method was determined by $12 \%$ SDS-PAGE and staining of the proteins with PageBlue (Fig. 1b). $1 \mu \mathrm{g}$ of the total protein was loaded into each lane. Each method resulted in equally pure protein bands corresponding to the size of the NoV capsid. Residual PEG present in the VLPs, concentrated by PEG dialysis, may have interfered with the protein concentration determination, and

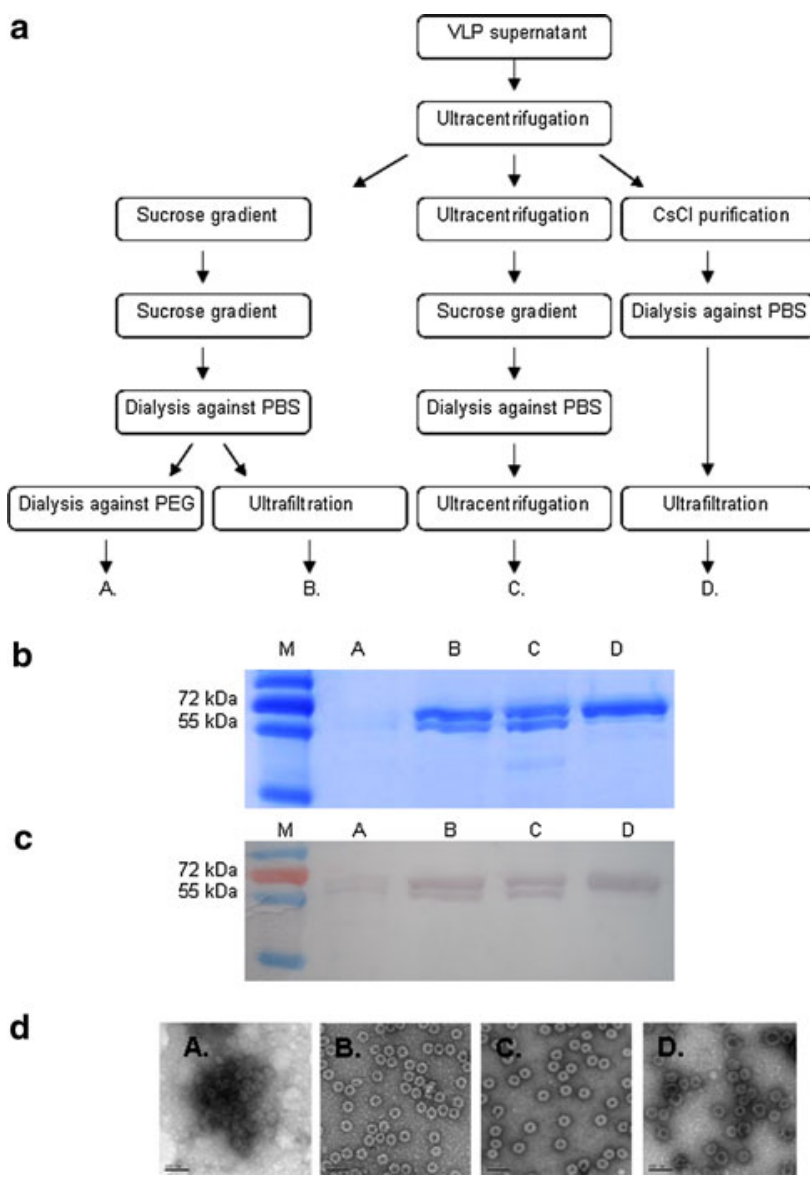

Fig. 1 Purification, concentration and characterization of NoV VLPs. a Several purification procedures $(A-D)$ were used, and the purity, morphology, antigenicity and yield of the VLPs were compared. b NoV capsid protein analysis by $12 \%$ SDS-PAGE. c Western blot analysis using a human convalescent serum against norovirus GII-4. d EM of purified NoV VLPs observed at a magnification of $\times 30,000$. Bar $100 \mathrm{~nm}$. Samples from purification procedures $A, B, C$, and $D$ correspond to lanes and panels $A, B, C$, and $D$, respectively. $M$ protein weight marker 
this could explain the lower capsid protein concentration observed (Fig. 1b, lane A). NoV capsid identity and antigenicity of the VLPs were assayed by western blot using human NoV-specific convalescent sera (Fig. 1c). The results show pure NoV capsid proteins without degradation and with similar antigenicity for each of the purification methods. Next, we determined the morphological integrity and homogeneity of the VLPs by EM (Fig. 1d). The VLPs obtained by purification with sucrose density gradients followed by dialysis and either ultrafiltration (Fig. 1d, panel B) or ultracentrifugation (Fig. 1d, panel C) were approximately $38 \mathrm{~nm}$ in size, with the classical appearance of NoV capsid VLPs. By contrast, $\mathrm{CsCl}$ purification (Fig. 1d, panel D) and concentration of the VLPs by dialysis against PEG (Fig. 1d, panel A) resulted in VLPs of heterogeneous size, which appeared broken and aggregated. The VLPs purified and concentrated by the method schematically presented in Fig. 1a, panel B, were of the best quality and were subjected to further analysis.

To determine the optimal storage conditions and stability of the NoV capsid VLPs, VLPs were treated under different conditions, and the samples were analyzed by SDS-PAGE to test their protein integrity (Fig. 2a) and by EM to examine their morphology (Fig. 2b). VLPs were stable for at least 12 months at $4^{\circ} \mathrm{C}$ in PBS, pH 7.4 (Fig. 2a and b, panel 1), and at room temperature $\left(23^{\circ} \mathrm{C}\right)$ up to 7 days (Fig. 2a and b, panel 3). The VLPs withstood the sterile filtration conditions when $0.22-\mu \mathrm{m}$ filters (Durapore, Millipore, Ireland) were used. Next, we intentionally disrupted the VLP morphology by heat treatment at $60^{\circ} \mathrm{C}$ for $1 \mathrm{~h}$ (Fig. 2b, panel 4) [1] without degrading the capsid protein (Fig. 2a, lane 4).

An HBGA binding assay $[8,18]$ was used to test the functionality of the purified VLPs as well as to determine the significance of the conformational binding sites on the VLP, which would presumable require intact VLPs. A comparison of the binding of VLPs purified by sucrose gradient centrifugation and by $\mathrm{CsCl}$ sedimentation, as well as
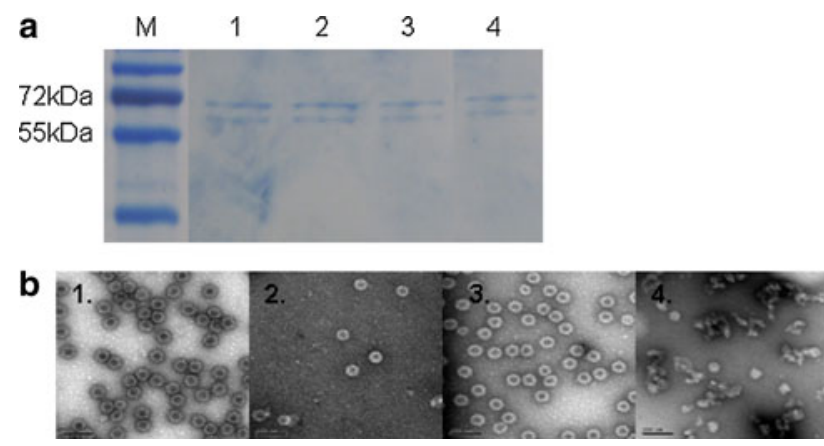

Fig. 2 Stability of NoV VLPs. The stability was analyzed by SDSPAGE (a) and EM (b) at a magnification of $\times 30,000$. Bar $100 \mathrm{~nm}$. NoV capsid VLPs after 8 months at $4^{\circ} \mathrm{C}$ (lane 1 and panel 1), sterile filtration (lane 2 and panel 2), 7 days at room temperature (lane 3 and panel 3) and heat treatment $\left(60^{\circ} \mathrm{C}, 1 \mathrm{~h}\right)$ (lane 4 and panel 4$)$ heat-treated VLPs $\left(60^{\circ} \mathrm{C}, 1 \mathrm{~h}\right)$, to synthetic biotinylated $\mathrm{H}$ type 3 carbohydrate is shown in Fig. 3. The binding was clearly dependent on the morphology and preserved structure of the VLPs, with the lowest level of binding observed with the heat-treated VLPs with disrupted conformational binding sites. Lewis ${ }^{\mathrm{b}}$ antigen was used as a control in the assay, and this did not bind to any of the VLPs (Fig. 3).

NoV VLPs have been used extensively to study protein interactions [8], and virus assembly [17], and have been used as a tool in diagnostic serological assays [7]. Clinical trials have been performed with the NoV VLPs used as a vaccine [2]. For all these applications, high-quality VLPs would be preferable. In this study, different methods of VLP purification and concentration were used, and the purity, integrity, morphology, antigenicity and functionality of the GII-4 NoV VLP preparations were examined.

VLPs purified by each method (Fig. 1a, methods A-D) had a similar appearance and migration pattern on the SDSPAGE gel. A western blot with a human convalescent serum from an individual infected with GII-4 confirmed the identity of the capsids and the lack of degradation products.

The reason for the lower protein yield after purification procedure $\mathrm{C}$ might have been that a narrow visible band of VLPs was collected from $35 \%$ sucrose, causing some of the protein to be omitted, thus affecting the yield. However, a yield of up to 2-3 mg of VLPs, which was obtained by the best purification method described in the present study, is remarkably high when compared to other reports [3, 4].

EM analysis of the morphological integrity and homogeneity of the VLPs showed that VLPs obtained by purification with sucrose density gradients followed by ultrafiltration or ultracentrifugation (procedures B and C,

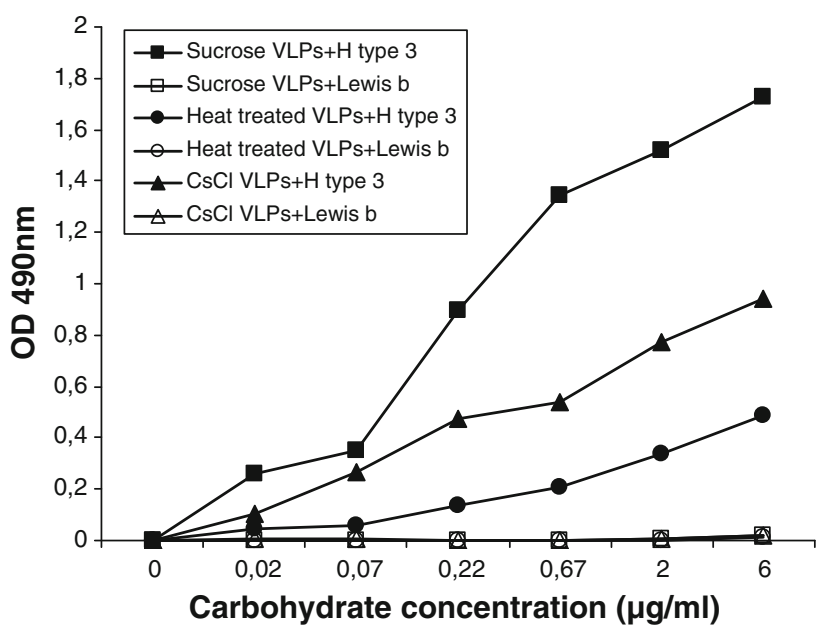

Fig. 3 Binding of NoV VLPs to synthetic ABH histo-blood group antigens. Sucrose-purified VLPs (Sucrose VLPs, purified according to procedure B in Fig. 1a), heat-denatured NoV VLPs $\left(60^{\circ} \mathrm{C}, 1 \mathrm{~h}\right)$ (Heattreated VLPs) and CsCl-purified VLPs (CsCl VLPs) were tested for binding to $\mathrm{H}$ type 3 and Lewis ${ }^{\mathrm{b}}$ carbohydrates at the indicated concentrations. The $\mathrm{pH}$ value in the binding assay was 7.4 
respectively) were homogenous and intact, and approximately $38 \mathrm{~nm}$ in size. However, CsCl-purified VLPs appeared heterogeneous in size, with a few broken particles, although comparable to the morphology seen by others [7]. $\mathrm{CsCl}$ purification is known to introduce several impurities at the end of the process and cause aggregation of the VLPs during storage [5]. The poorest morphology was seen after concentration of the VLPs by dialysis against PEG, which resulted in aggregation. In addition, residual PEG, which leaks through the dialysis membrane, might interfere with further applications of the VLPs [19].

Our data clearly demonstrate that the purification process affects the integrity of the native quaternary structure of NoV VLPs and, subsequently, the receptor-binding functionality of the VLPs. Although the majority of the VLPs purified by the $\mathrm{CsCl}$ method seemed intact in the EM image, the difference from sucrose-density-gradient-purified VLPs in HBGA binding is striking. This result is supported by the recent finding that $\mathrm{CsCl}$ has a negative impact on the functionality of VLPs [5]. We also demonstrated that even heat-disrupted VLPs have binding capability, but intact homogenous VLPs have a significantly greater binding intensity. Standardization of the purification method for NoV VLPs used in diagnostic serological assays and blocking assays [8] would greatly strengthen the results obtained.

To the best of our knowledge, this is the first time that VLPs purified by conventional purification and concentration methods were compared in terms of yield, purity, morphological integrity, antigenicity and functionality. The results show that NoV GII-4 VLPs purified twice by sucrose density gradient centrifugation followed by ultrafiltration maintain their icosahedral capsid structure and their capacity to bind HBGAs.

Acknowledgments We thank Eija Jokitalo and Helena Vihinen for their guidance and assistance with transmission electron microscopy. We also thank Eeva Jokela for technical assistance during the study and Marjo Salminen for support in laboratory work.

Open Access This article is distributed under the terms of the Creative Commons Attribution Noncommercial License which permits any noncommercial use, distribution, and reproduction in any medium, provided the original author(s) and source are credited.

\section{References}

1. Ausar SF, Foubert TR, Hudson MH et al (2006) Conformational stability and disassembly of Norwalk virus-like particles. Effect of $\mathrm{pH}$ and temperature. J Biol Chem 281:19478-19488. doi: 10.1074/jbc.M603313200

2. Ball JM, Graham DY, Opekun AR et al (1999) Recombinant Norwalk virus-like particles given orally to volunteers: phase I study. Gastroenterology 117:40-48

3. Belliot G, Noel JS, Li JF et al (2001) Characterization of capsid genes, expressed in the baculovirus system, of three new genetically distinct strains of "Norwalk-like viruses". J Clin Microbiol 39:4288-4295. doi:10.1128/JCM.39.12.4288-4295.2001

4. Bertolotti-Ciarlet A, Crawford SE, Hutson AM et al (2003) The $3^{\prime}$ end of Norwalk virus mRNA contains determinants that regulate the expression and stability of the viral capsid protein VP1: a novel function for the VP2 protein. J Virol 77:11603-11615

5. Burova E, Ioffe E (2005) Chromatographic purification of recombinant adenoviral and adeno-associated viral vectors: methods and implications. Gene Ther 12(Suppl 1):S5-S17. doi: 10.1038/sj.gt.3302611

6. Degerli N, Akpinar MA (2001) A novel concentration method for concentrating solutions of protein extracts based on dialysis techniques. Anal Biochem 297:192-194. doi:10.1006/abio.2001.5335

7. Hansman GS, Natori K, Shirato-Horikoshi H et al (2006) Genetic and antigenic diversity among noroviruses. J Gen Virol 87:909-919. doi:10.1099/vir.0.81532-0

8. Harrington PR, Lindesmith L, Yount B et al (2002) Binding of Norwalk virus-like particles to $\mathrm{ABH}$ histo-blood group antigens is blocked by antisera from infected human volunteers or experimentally vaccinated mice. J Virol 76:12335-12343

9. Jiang X, Wang M, Graham DY et al (1992) Expression, selfassembly, and antigenicity of the Norwalk virus capsid protein. J Virol 66:6527-6532

10. Jiang X, Wang M, Wang K et al (1993) Sequence and genomic organization of Norwalk virus. Virology 195:51-61. doi:10.1006/ viro.1993.1345

11. Koho T, Teräväinen L, Blazevic V, Nurminen K, Butcher S, Laurinmäki P, Kalkkinen N, Rönnholm G, Vesikari T, Hytönen VP, Kulomaa MS. Production and characterization of virus-like particles and P domain protein of GII.4 Norovirus. J Virol Methods (submitted)

12. Lew JF, Valdesuso J, Vesikari T et al (1994) Detection of Norwalk virus or Norwalk-like virus infections in Finnish infants and young children. J Infect Dis 169:1364-1367

13. Lopman B, Vennema H, Kohli E et al (2004) Increase in viral gastroenteritis outbreaks in Europe and epidemic spread of new norovirus variant. Lancet 363:682-688. doi:10.1016/S0140-6736 (04) $15641-9$

14. Lu X, Chen Y, Bai B et al (2007) Immune responses against severe acute respiratory syndrome coronavirus induced by viruslike particles in mice. Immunology 122:496-502. doi:10.1111/ j.1365-2567.2007.02676.x

15. Makidon PE, Bielinska AU, Nigavekar SS et al (2008) Preclinical evaluation of a novel nanoemulsion-based hepatitis B mucosal vaccine. PLoS One 3:e2954. doi:10.1371/journal.pone. 0002954

16. Peixoto C, Sousa MF, Silva AC et al (2007) Downstream processing of triple layered rotavirus like particles. J Biotechnol 127:452-461. doi:10.1016/j.jbiotec.2006.08.002

17. Prasad BV, Rothnagel R, Jiang X et al (1994) Three-dimensional structure of baculovirus-expressed Norwalk virus capsids. J Virol 68:5117-5125

18. Rockx B, Baric RS, de Grijs I et al (2005) Characterization of the homo- and heterotypic immune responses after natural norovirus infection. J Med Virol 77:439-446. doi:10.1002/jmv.20473

19. Russell BJ, Velez JO, Laven JJ et al (2007) A comparison of concentration methods applied to non-infectious flavivirus recombinant antigens for use in diagnostic serological assays. J Virol Methods 145:62-70. doi:10.1016/j.jviromet.2007.05.008

20. Tan M, Zhong W, Song D et al (2004) E. coli-expressed recombinant norovirus capsid proteins maintain authentic antigenicity and receptor binding capability. J Med Virol 74:641-649. doi:10.1002/jmv.20228

21. Zheng DP, Ando T, Fankhauser RL et al (2006) Norovirus classification and proposed strain nomenclature. Virology 346:312-323. doi:10.1016/j.virol.2005.11.015 